\title{
Effect of Herbal Liver Stimulants on the Performance of Hy-line Commercial Layer
}

\author{
Damodar Neupane $^{1}$, Mukesh Karki ${ }^{1}$, C.R. Upreti ${ }^{2}$ and Tribhuveneshor Dhaubhadel ${ }^{\mathbf{1}}$ \\ ${ }^{1}$ Swine and Avian Research Program, ${ }^{2}$ Animal Nutrition Research Division \\ Nepal Agricultural Research Council, Khumaltar, Lalitpur
}

\begin{abstract}
An investigation was undertaken on 180 day-old Hy-line layer chicks to assess the effect of herbal products on feed consumption, egg production and profitability. The experimental chicks were randomly divided in three groups with three replicates in each and were housed in identical management and environmental conditions. Dietary treatments were prepared by addition of herbal liver stimulants such as Livoliv $250 @ 500 \mathrm{~g} / \mathrm{ton}$ (D2) and Superliv @ 500g/ton (D3) in the basal diet (D1). Feed intake, egg production and mortality were recorded throughout the observation period of 50 weeks. Feed per unit of egg production, hen day percentage, additional income of supplemented diet over the basal diet were calculated. Average daily intake $(\mathrm{g})$ of the diets per bird were observed as $59.19 \pm 1.05 \mathrm{~g}$, $58.31 \pm 0.337 \mathrm{~g}$ and $57.67 \pm 0.163 \mathrm{~g}$ up to 20 weeks and $108.94 \pm 0.06 \mathrm{~g}, 109.01 \pm 0.05 \mathrm{~g}$ and $108.26 \pm 0.41 \mathrm{~g}$ during the laying period fed with D3, D1 and D2 diets respectively. Similarly, higher hen day egg \% (76.9\%) was recorded in the birds fed with Superliv supplemented diet (D3), followed by Livoliv supplemented diet (D2) (73.4\%) and Basal diet (D1) $(72.1 \%)$ with feed intake per unit egg production of $179.3 \mathrm{~g}, 178.1 \mathrm{~g}$ and $193.0 \mathrm{~g}$, respectively. Total egg production was found higher with D3 (161.49 egg), followed by D2 (154.15 egg) and basal diet (151.45 egg) with layer house cumulative mortality only in D3 (3.75\%). Additional profits of Rs. 35.18 and Rs. 12.86 in terms of egg selling over feed cost per layer were calculated for the bird fed with Superliv supplemented diet (D3) and Liveloliv supplemented diet (D2) than that of the basal diet.
\end{abstract}

Key words: layer, herbal products, liver stimulant, feed efficiency, profit

\section{Introduction}

Poultry keeping is important in Nepalese farming system from ancient times till today. Chicken is one of the most important poultry species that has played a major role in the livelihood of Nepalese, not only as a nutritional source of food but also for its economic and religious role. The present production of chicken egg in Nepal is around 600.96 million, between 1995/96 and 2006/07, the egg production in the country has been found to be increased by $157.98 \%$ (MOAC 2007). Similarly, during the past three decades global egg production has also shown a remarkable increase (FAOSTAT 2006). It is encouraging to see that an increasing demand for eggs because of the higher buying capacity of the population as well as their changing dietary habit clearly indicates favorable prospects and potential of egg production in the country. In the mean time, industrialization of the chicken production is occurring rapidly in the country which inevitably leads chicken egg production to competitive market oriented enterprises accompanied with some constraints. Expensive and substandard quality of feed is commonly a major constraint to secure profitability in the competitive edge in the market along with consumers' awareness towards quality products. It is obvious that feed cost constitute about $70 \%$ of production cost in poultry production. So lowest possible feed price is essential for profitable production. Eggs are the major bussiness outputs in commercial table egg production and the higher the egg production the better will be the profit. In general, in chicken egg laying starts at 20-22 weeks of age and individual bird is expected to lay 270 eggs by the age of 75 weeks with consumption of $1.8 \mathrm{~kg}$ of feed for each dozen of eggs (Parkhurst \& Mountney 2004). Verma and Singh (1997) have reported $87.3 \%$ contribution of egg to the total returns of poultry industry.

Some early studies showed that continuous feeding of antibiotics as growth stimulants to chicken resulted in a decreased growth response (Guo et al. 2004). Importantly, some countries have already bans on use of antibiotics in chicken production due to growing concern of antibiotics residues in the meat and eggs and on possibly increasing bacterial resistant and their potential transfer from birds to man via the food chain (Casewell et al. 2003, Cunha 2007). 
Therefore there is a need to explore possible alternatives to ensure sustainable productivity and profitable egg production in the country. Herbal products have been reported to be effective growth promoters in chicken production (Guo et al. 2004, Islam et al. 2005).

Work carried out in others countries have shown positive effect of herbal liver stimulants on performance of chicken (Chatterjee \& Agrawala 2002, Singh et al. 2002, Mishra et al. 2004). Chatterjee and Agrawala (2002) further reported that supplementation of herbal liver stimulants improved gastro-intestinal microenvironment of the birds and thereby enhanced utilization of nutrients and ultimately increased in productivity without possing any adverse effect on animal systems. Roy et al. (1994) reported better quality eggs in addition of $3.08 \%$ higher number with Livoliv supplemented diet compared to control. Neupane and Karki (2008) found positive effect of Livoliv on body weight, dressing percentage and profitability of broiler under Nepalese condition. However, the effect of herbal liver stimulants on performance in egg production of layer is not yet investigated in Nepal. Therefore, this trial was designed to assess the effects of Livoliv and Superliv on feed consumption, egg production and economics of layers under Nepalese condition.

\section{Materials and Methods}

The present investigation was undertaken on 180 dayold Hy-line layer chicks to assess the effect of herbal products on feed consumption, egg production and profitability. The experimental chicks were randomly divided in three groups with three replicates in each and were housed in identical management and environmental conditions. Dietary treatments were prepared by addition of herbal liver stimulants Livoliv $250 @ 500$ g/ton (D2) and Superliv @ 500g/ton (D3) in the basal diet (D1). The commercially available layer starter/finisher diet that most commonly used by farmers in the country was used as basal diet. Feed intake, egg production and mortality were recorded throughout the observation period of 50 weeks and feed per unit of egg production, hen day percentage and economics in terms of egg selling income over feed cost per layer was calculated including the extra supplemented charge. The data collected from the experiment were analyzed using MINITAB statistical package.

\section{Results and Discussion}

The average value $( \pm \mathrm{SE})$ of feed intake, egg production, mortality and economics in terms of egg selling over feed cost are given in Table 1. No remarkable difference was observed on daily feed intake of birds between the dietary treatments during both growing and laying period. Including the supplemented charge, slightly higher feed cost per bird was calculated for Superliv supplemented diet (Rs 574) as compared to control (Rs 569). Though, initial days of laying was slightly delayed for supplemented diet compared to control, the difference was non-significant. Lower chicks mortality $(1.67 \%)$ was observed in Superliv supplemented bird during the growing periods where as layer house mortality was found only in Livoliv supplemented diet. Irrespective of dietary treatments, the overall mortality recorded in this experiemnt was very low than reported by Bhurtel and Shaha (2000) under the Nepalese layer farms condition.

Table 1. Effect of herbal supplemented diet on feed intake, egg laying and economics of layers production

\begin{tabular}{|c|c|c|c|}
\hline \multirow[t]{2}{*}{ Particulars } & \multirow[t]{2}{*}{ Non-supplemented } & \multicolumn{2}{|l|}{ Supplemented } \\
\hline & & Livoliv $(500 \mathrm{~g} / \mathrm{t})$ & Superliv $(500 \mathrm{~g} / \mathrm{t})$ \\
\hline Feed intake (g/day) up to growing (0-20 weeks) & $58.31 \pm 0.337$ & $57.67 \pm 0.163$ & $59.19 \pm 1.05$ \\
\hline Feed intake (g/day) during laying (21-50) & $109.01 \pm 0.05$ & $108.26 \pm 0.41$ & $108.94 \pm 0.06$ \\
\hline Total feed cost $(0-50)$ weeks per bird & Rs 569.11 & Rs 567.05 & Rs 574.08 \\
\hline Initial days of laying (10\%) & $144.67 \pm 1.76$ & $147.67 \pm 3.18$ & $147.33 \pm 1.76$ \\
\hline Mortality up to 20 weeks & $5 \%$ & $5 \%$ & $1.67 \%$ \\
\hline Mortality during laying (21-50 week) & - & 3.75 & - \\
\hline Hen day egg $\%$ & 72.1 & 73.4 & 76.9 \\
\hline Feed intake /unit of egg & $193.0 \pm 8.41 \mathrm{gm}$ & $178.1 \pm 3.87 \operatorname{gm}(-7.72 \%)$ & $179.3 \pm 9.24 \operatorname{gm}(-7.09 \%)$ \\
\hline Feed intake per dozen of eggs & $2.316 \pm 0.101 \mathrm{~kg}$ & $2.138 \pm 0.046 \mathrm{~kg}$ & $2.151 \pm 0.111 \mathrm{~kg}$ \\
\hline Egg/hen/day & $0.721 \pm 0.012$ & $0.734 \pm 0.006$ & $0.769 \pm 0.027$ \\
\hline Total egg up to 50 weeks & $151.45 \pm 2.60 \mathrm{egg}$ & $154.15 \pm 1.33 \mathrm{egg}$ & $161.49 \pm 5.81 \mathrm{egg}$ \\
\hline Income selling egg (Rs 4 per egg) & Rs 605.8 & Rs 616.6 & Rs 645.96 \\
\hline Saving over feed cost & Rs 36.69 & Rs 49.55 & Rs 71.87 \\
\hline Additional profit per bird & & Rs. 12.86 & Rs. 35.18 \\
\hline
\end{tabular}


Hen day egg $\%$ was recorded higher $(76.9 \%)$ in the birds fed with Superliv supplemented diet (D3), followed by Livoliv supplemented diet (D2) $73.4 \%$ and Basal diet (D1) $72.1 \%$ with consuming $179.3 \pm 9.24 \mathrm{~g}, 178.1 \pm 3.87$ $\mathrm{g}$ and $193.0 \pm 8.41 \mathrm{~g}$ of feed per each unit of egg production, respectively. Similarly, total egg production was found higher with D3 (161.49 eggs), followed by D2 (154.15 eggs) and basal diet (151.45 eggs). Data revealed that birds fed with supplemented diet consumed about $7 \%$ less feed for each unit of egg production as compared to the control group, however, not efficient than quoted by Parkhurst and Mountney (2004). The egg production trends of laying period are given in Table 2. It is fact that irrespective of dietary treatment, the egg production was observed lower at initial period of laying and remained peak duing the periods of 25-32 weeks, then slightly declined. The laying periods of 2532 weeks was found very efficient and economical.
Saving in terms of income from selling eggs over feed cost was found higher in Superliv supplemented diet (Rs 71.87), followed by Livoliv supplemented diet (Rs 49.55). Additional profits of Rs. 35.18 and Rs. 12.86 in terms of egg selling over feed cost per layer were calculated for the birds fed with Superliv supplemented diet (D3) and Livoliv supplemented diet (D2) than that of the basal diet. Based on this observation, it can be concluded that supplementation of herbal liver stimulants (Livoliv and Superliv ) are beneficial for improving laying performance as well as profitability of layer. However, further research needs to be conducted in future with emphasizing utilization of different domestic herbs of the country and their appropriate concentration.

Table 2. Hen day $\%$ and feed consumption per unit of egg production at different periods of laying

\begin{tabular}{lcccccc}
\hline \multicolumn{2}{c}{ Age (week) } & \multicolumn{3}{c}{ Hen day percentage } & \multicolumn{3}{c}{ Feed per unit of egg production $(\mathrm{g})$} \\
\hline $21-24$ & $\mathrm{D} 1$ & $\mathrm{D} 2$ & $\mathrm{D} 3$ & $\mathrm{D} 1$ & $\mathrm{D} 2$ & D3 \\
$25-28$ & $39.8 \pm 0.94$ & $29.1 \pm 2.20$ & $34.0 \pm 3.92$ & $489.0 \pm 45.5$ & $403.0 \pm 42.5$ & $464.0 \pm 44.2$ \\
$29-32$ & $82.4 \pm 2.21$ & $84.3 \pm 2.40$ & $85.2 \pm 3.66$ & $128.5 \pm 3.25$ & $125.5 \pm 2.82$ & $125.1 \pm 5.13$ \\
$33-36$ & $83.2 \pm 0.72$ & $86.4 \pm 0.95$ & $88.3 \pm 2.95$ & $130.8 \pm 2.87$ & $127.2 \pm 1.54$ & $124.7 \pm 2.73$ \\
$37-40$ & $77.0 \pm 0.45$ & $75.3 \pm 1.25$ & $85.4 \pm 2.56^{*}$ & 144.60 .70 & $146.2 \pm 3.45$ & $129.7 \pm 3.83^{*}$ \\
$41-44$ & $76.4 \pm 2.79$ & $77.1 \pm 0.59$ & $82.7 \pm 3.22$ & 149.85 .26 & $146.7 \pm 1.76$ & $137.2 \pm 5.49$ \\
$45-48$ & $76.0 \pm 1.86$ & $82.5 \pm 1.88$ & $81.4 \pm 2.19$ & $153.6 \pm 4.38$ & $140.9 \pm 3.89$ & $142.3 \pm 3.75$ \\
& $71.8 \pm 2.75$ & $75.3 \pm 1.69$ & $78.9 \pm 2.66$ & $163.0 \pm 6.57$ & $172.0 \pm 14.5$ & $148.0 \pm 5.10$ \\
\hline
\end{tabular}

Means bearing * in a row of same parameter differ significantly $(\mathrm{P}<0.05), \mathrm{D} 1$ : Control, D2: D1+ Livoliv @ 500g/ton and D3: D1 +Superliv@500g/ton

\section{Acknowledgement}

We are highly thankful to Dabar Nepal and Indian Herb Limited for providing herbal liver stimulants used in the research. Similarly, thanks go to Director, Livestock and Fisheries Research and Dr. Rama Bhurtel, Swine and Avian Research Program for encouraging us to conduct this important research.

\section{References}

Bhurtel, R. and B.K.P. Shaha. 2000. Poultry development in Nepal-Constraints and potentials. Winkrock International research paper. p. 45, 51.

Casewell, M., C. Friis, E.Marco, P.McMullin and I.Phillips. 2003. The Europe ban on growth-promoting antibiotics and emerging consequences for human and animal health. Journal of Antimicrobial Chemotherapy 52: 159-161.

Chatterjee, S. and S.K. Agrawala. 2002. From the concept of simple liver tonic of previous generation to "Livoliv": A new generation poultry performance enhancing system. Phytomedica 3:13-25.

Cunha, R.G.T. 2007. Probiotics: who lets the bugs out. World Poultry 23 (9) : 14-16.

FAOSTAT. 2006. Food and Agriculture Organization of the United Nations. http://faostat.fao.org/site/342/ default.aspx

Guo, F.C., R.P. Kwakkel, J.Soede, B.A. Willams and M.W.A. Verstegen. 2004. Effect of Chinese herb medicine 
formulation as an alternative for antibiotics, on performance of broilers. British Poultry Science 45(6) : 793-797.

Guo, F.C., R.P.Kwakkel, B.A. Williams, W.K. Li, H.S. Li, J.Y. Luo, X.P.Li, Y.X.Wei, Z.T. Yan and M.W.A. Verstegen. 2004. Effects of mushroom and herb polysaccharides as alternatives for an antibiotic, on growth performance of broilers. British Poultry Science 45 (5) : 684-694.

Islam, R.; J. D. Mahanta and D. Sapcota. 2005. Effect of herbal liver stimulant on the performance of commercial broilers. Indian Journal of Animal Sciences 75 (5) : 545-546.

Mahajan, P., J. Sahad and P.C. Panda. 1999. Effect of probiotic feeding and seasons on the growth performance and carcass quality of broilers. Indian J. Poult. Sci. 34 (2) : 167-176.

Mishra, P.K., S.C. Mishra and P.K. Dehuri. 2004. Effect of Livoliv as a growth promoter in broiler chicken. Livestock International 8 (12) : 12-15.
MOAC. 2007. Statistical information on Nepalese Agriculture 2004/05. Government of Nepal, Minisrty of Agriculture and Cooperative, Agri-Business, Production and Statistical Division, Singha Darbar, Kathmandu, Nepal.

Neupane, D. and M. Karki. 2008. Effect of herbal liver stimulant (Livoliv) on the feed consumption, FCR, weight gain and economics of commercial broilers. Paper presented in the Second Convention of Society of Agriculture Scientists, Nepal.

Parkhurst, C.R. and G.J. Mountney. 2004. Commercial egg production and Poultry meat and egg production. CBS Publishers and Distributors, New Delhi. p. 294.

Roy, S, R.C. Ghose and B.R. Patle. 1994. Effect of Livoliv PFS on the egg production of layers. Indian J.Indg. Med. 11: 63-66.

Singh, M., S. D. Sharma, R. K. Sharma and S. S. Chauhan. 2002. Efficacy of Livoliv for improving performance and carcass quality of broilers. Phytomedica 3 : 49-54.

Verma, L. C. and K.S. Singh. 1997. Cost and returns structure in layer farming. Indian J. Poult. Sci. 32 (2) : $152-158$. 